\title{
INFLUENCE OF SETTLEMENTS AND GEOMETRICAL IMPERFECTIONS ON THE INTERNAL STRESS STATE OF MASONRY STRUCTURES
}

\author{
A. DELL'ENDICE ${ }^{1 *}$, A. IANNUZZO ${ }^{1}$, T. VAN MELE ${ }^{1}$ AND P. BLOCK ${ }^{1}$ \\ ${ }^{1}$ Institute of Technology in Architecture (ITA), Block Research Group (BRG) \\ Eidgenössische Technische Hochschule Zürich (ETH - Zurich) \\ Stefano-Franscini-Platz 1, HIB E, CH-8093 Zurich, Switzerland \\ email: \{dellendice, iannuzzo, block, van.mele\}@arch.ethz.ch,www.block.arch.ethz.ch
}

Keywords: Masonry Structures, Discrete Element Modelling, Geometrical imperfections, Settlements, Internal Stress State

\begin{abstract}
Since a few decades, the Discrete Element Modelling (DEM) method has been adopted by many authors as a reliable tool for the structural assessment of unreinforced masonry (URM) structures. In this paper, through compas_dem and using 3DEC by Itasca as a solver in the background, we investigate the mechanical behaviour of a three-dimensional URM structure combining the effects of foundation displacements and geometrical imperfections. For this purpose, we consider three different models of the above-mentioned structure. The first one is a perfect digital model, while in the other remaining two models, random geometrical imperfections are applied to the perfect model in order to investigate their influence. After post-processing the 3DEC results, the influence of the applied vertical settlement and geometrical imperfections is explored in terms of crack pattern/mechanism, internal stress states, and the thrust exerted on the supports. The aim of this paper is not to find the actual stress state of the highly indeterminate structure, but to investigate the role played by the combined effects of foundation displacement and geometrical imperfections on the internal stress state.
\end{abstract}

\section{INTRODUCTION}

The structural assessment of unreinforced masonry (URM) structures represents one of the most common challenges for engineers in everyday practice. This structural typology is diffused worldwide and includes both historical monuments and residential buildings. In the last century, the essential knowledge for both designing and restoring these structures has been forgotten, and methods and tools for the structural design of reinforced concrete, steel and wooden buildings took over. These methods (e.g. linear or non-linear Finite Element Analysis), even though able of handling complex three-dimensional geometries, are often based on stress/strength approaches and, in order to be applicable to URM, require a refined mechanical characterisation based on parameters that, in most cases, are unknown or unknowable. Furthermore, since it is well known that the stability of masonry structures depends on their geometry rather than on the material's strength [1], these approaches often lead to "unsafe and deceptive results," as explained in [2]. In 1966, Heyman introduced a theoretical framework for 
the application of limit analysis to masonry structures through three assumptions that showed the important role of the geometry in the stability of this structural typology. One of the oldest methods used for the assessment of masonry structures that perfectly fits inside the limit analysis framework is the Thrust Line Analysis (TLA). This powerful method is used since centuries and describes the behaviour of the masonry structure very well [3]. Its downside is that is primarily a 2D approach. For the analysis of the 3D behaviour, other limit-analysis methods such as Thrust Network Analysis [4][5], or compressive equilibrium membranes [6][7][8][9], have been developed. Most of these methods apply the Safe Theorem [1], meaning that they assess the stability of masonry structures through lower-bound solutions. Additionally, they have been developed for vaulted geometries, i.e. height fields.

To deal with complex 3D geometries, more generally intricate assemblies, and to account for their typical unilateral behaviour [10], the Discrete Element Modelling (DEM) method developed by [11] can be applied. The DEM method aims to represent the structural behaviour of a system composed of multiple bodies analysed as distinct units in mutual contact at the joints. Several mechanical assessment problems can be tackled: stability in a given configuration, load-bearing capacity, dynamic loading conditions, and the effects of large settlements. Moreover, the possibility offered by the DEM software 3DEC by Itasca $[12][13][14]$ to work in three dimensions helps in the investigation of collapse mechanisms and in understanding the global behaviour of complex geometries [15][16][17][18][19]. The importance to understand the 3D behaviour and the interaction between structural elements of

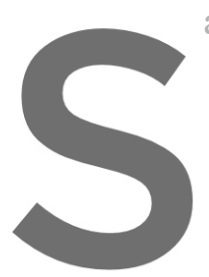
a masonry building is
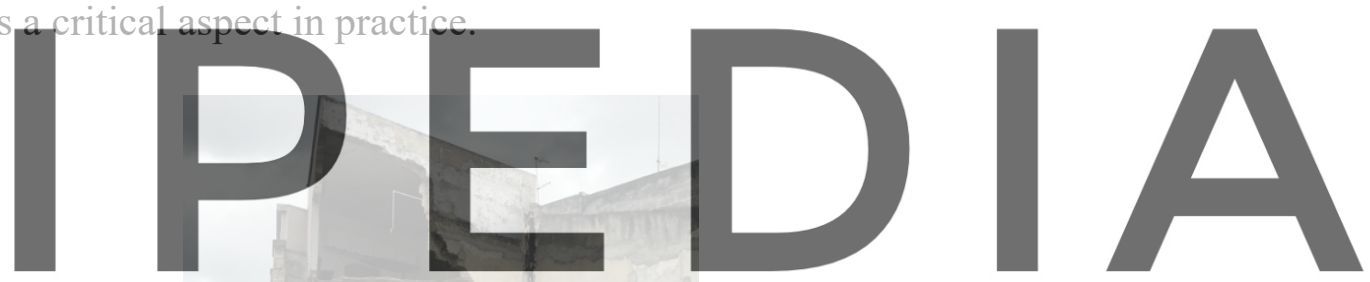

Register for free at https//www.scipedia.com to download the version without the watermark

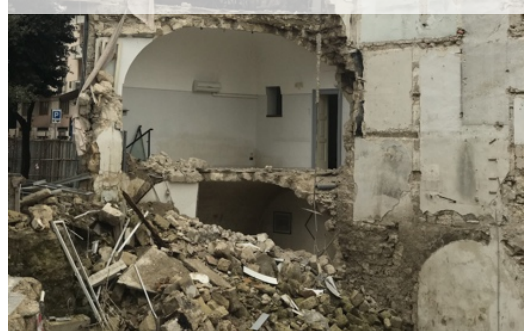

Figure 1. Partial collapse of a building after the demolition of the adjacent building (Oct 2019, Andria, Italy).

In many cases, analysis of the global behaviour of the entire building is necessary. Moreover, in historical city centres, intervening on a masonry building often involves the study of several interconnected structures. Sometimes, the negligence in tackling these structural problems can cause sudden collapses (Fig. 1) and the loss of human lives. This paper aims to investigate the influence of vertical settlements and geometrical imperfections on the internal stress state of a buttressed wall structure using the DEM software 3DEC. Even though 3DEC allows 
investigating the behaviour of 3D structures, in this paper, the authors provide an extension to what was already available in 3DEC, post-processing the results to visualise the flow of forces within the structure for varying boundary conditions. Finally, the elaboration of the results helps in the analysis of the magnitude and position of the reaction forces at the supports.

\section{METHODOLOGY}

In this paper, DEM analysis using the software 3DEC by Itasca is performed. In particular, the stability in the initial configuration and the effects of a vertical settlement and geometrical imperfections are investigated. In this section, we provide a short overview of DEM, how we apply imperfections and how we post-process the results.

\subsection{Discrete Element Modelling}

DEM software has three main peculiarities: the model consists of finite-size bodies able to move and deform independently; large displacements are possible; and the blocks can completely detach from each other, possibly forming new contacts between other blocks. Static and dynamic behaviour can be simulated. The DEM method is widely accepted for the analysis of URM and it can, as stated in [20], approximate Heyman's assumptions [1]. The whole system's deformability, considering rigid blocks, is concentrated at the joints, and it is controlled by two parameters: the normal and shear joint stiffness. Physically, the two values of the joint stiffnesses influence, respectively, the compenetration and the sliding between

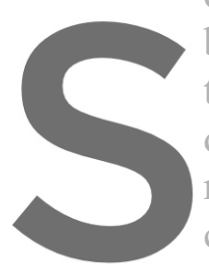
blocks. High values of joint stiffness should be
the analysis, although this notably increases
described in [16] and [19], the values of the jo
range, without infludncing the results of the
calculation time as well. The two joint stiffnes
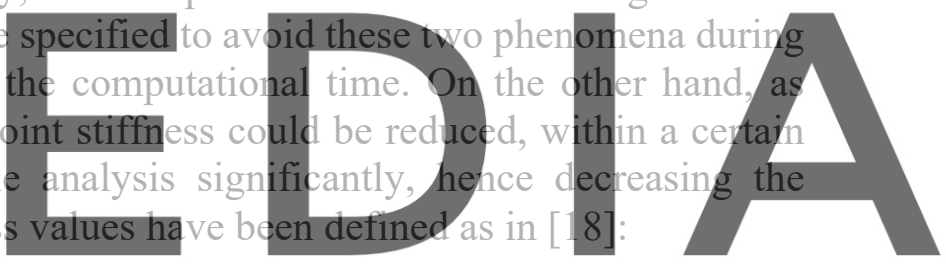

Register for free at https//www.scipedia. $d o m=\left(\frac{E}{\frac{h_{b l o c k}}{h_{b l o c k}}}\right)$ downloald the version without the watermark

where $J_{k n}$ is the normal joint stiffness, $E$ is the Young's modulus of the material, $h_{b l o c k}$ and $l_{\text {block }}$ are the average block height and block length, respectively.

For the evaluation of the joint shear stiffness, the Young's modulus $E$ has been replaced by the shear modulus $G$ defined as:

$$
G=\frac{E}{2(1+v)} \quad,
$$

where $v$ is the Poisson's coefficient considered equal to 0.2 . Then, the value of the shear joint stiffness has been evaluated as:

$$
J_{k s}=\left(\frac{\frac{G}{h_{\text {block }}}+\frac{G}{\text { lblock }}}{2}\right) .
$$

Regarding failure at the joints, the Mohr-Coulomb criterion is adopted:

$$
\tau=\sigma \tan (\phi)+c
$$

where $\tau$ is the shear strength, $\sigma$ the normal stress, $\phi$ the friction angle and $c$ the cohesion. In the Mohr-Coulomb criterion, considering Heyman's assumptions, the only parameter needed is the 
friction angle, as the value of cohesion is considered equal to zero. Finally, next to the two joint stiffness values and the friction angle, the fourth and last mechanical parameter needed is the density of the block's material. The reduced number of mechanical parameters needed allows limiting the dependency on input data that is based on uncertainty, especially in the assessment of historical masonry structures.

\subsection{Geometrical imperfections}

Real structures contain imperfections due to element geometry deviations or assembly errors. As shown in [19], imperfections influence the flow of forces within the structure. They redirect the forces accordingly to the imperfect contact conditions between the blocks and have an influence on the displacement capacity or the collapse mechanisms. Using the Python-based package compas_dem, part of the COMPAS Masonry framework [21], geometrical imperfections have been applied to the perfect digital model. In particular, element (e.g. due to fabrication) and assembly errors are generated (Fig. 2). For the former, each vertex of the blocks is randomly moved in space, picking the value of the displacement in a specific predefined range using a uniform distribution. For the latter, a random uniform distribution of displacement values, one per block, is generated within a certain range, and each block is moved according to it.
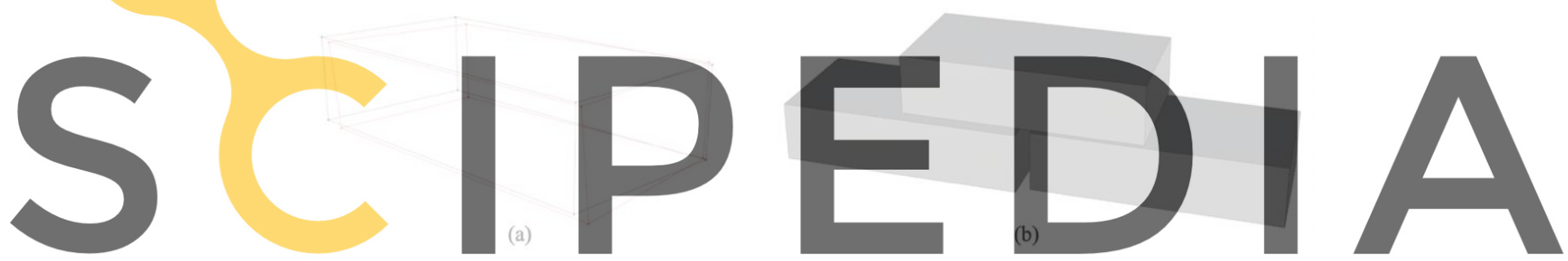

Figure 2. Geometrical imperfections in [19]: element geometry deviations (a); assembly errors (b).

Register for free at https//www.scipedia.com to download the version without the watermark 2.3 Post-processing of the results

In this paper, at each step of the analysis, the contact forces caiculated by $3 \mathrm{DEC}$ are postprocessed, and their resultants at each contact interface computed. Then, the resultants are visualised in a CAD software, together with the updated geometry of the digital model. The visualisation of the internal stress state at each step of the calculation allows following the variation due to the changing of the boundary conditions.

\section{MODELS}

In this paper, we look at the geometry depicted in Fig. 3, representing a typical structural portion of a church in between two buttresses. The structure is $15 \mathrm{~m}$ tall having openings at different levels. The lateral wall and the pillars are connected in the upper part by two flying buttresses and in the lower part by two walls. The two transversal buttresses also have an opening at the base. Three digital models of the same structure are considered: the first is the perfect digital model, that is, all the blocks have a regular shape resulting in perfect face-to-face contact conditions; the other two models are obtained by applying random distributions of geometrical imperfections of both types. 

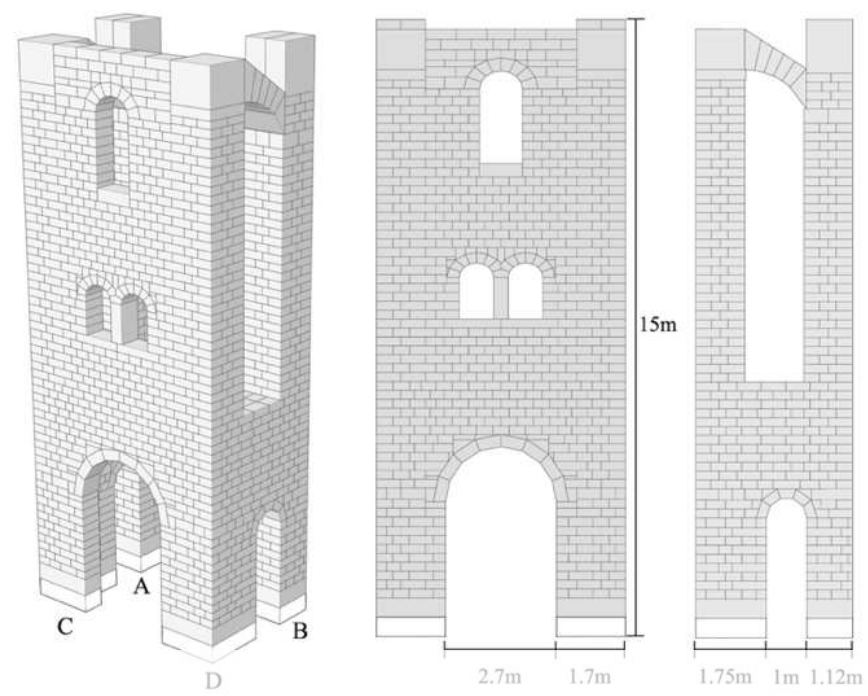

(b)

Figure 3. Digital three-dimensional model used in this paper: 3D view (a); front view (b); lateral view (c).

\subsection{Geometry and discretisation}

The geometry is generated using compas_dem, a Python-based package that can manage data structures and create diserete assemblies $A$ closed mesh represents each block, and through compas_dem, gec_entis model is made with a the blocks are $220 \mathrm{~mm}$ are discretised considering cuts perp

(pillars-wall, buttresses-base, etc.) are linked togen

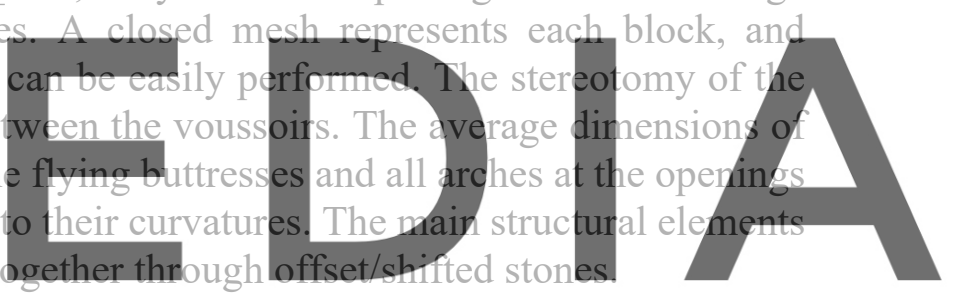

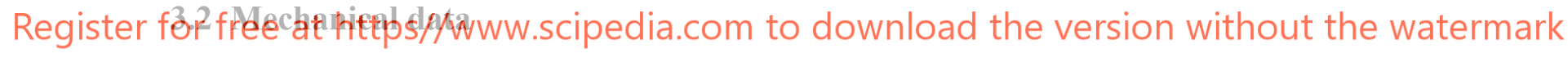

In the analyses, the blocks are considered rigid interacting with their neighbours through unilateral contacts. As explained in Section 2.1, the only mechanical parameters needed by 3DEC to define the mechanical behaviour of the contacts are the friction angle and two joint stiffness values. We consider a material density of $2200 \mathrm{Kg} / \mathrm{m}^{3}$, and a friction angle of $50^{\circ}$. The two joint stiffnesses (normal and shear) have been evaluated using Equations (1) and (3) assuming a Young's modulus of $40 \mathrm{GPa}$, hblock equal to $0.22 \mathrm{~m}$ and $l_{\text {block }}$ equal to $0.4 \mathrm{~m}$. These two values have then been reduced by a factor of 10 to reduce the calculation time.

\subsection{Geometrical imperfections}

The two digital, imperfect models are obtained by applying geometrical imperfections to the perfect model shown in Fig. 3. In the first one, named "imperfections 1", only element deviations are applied, that is, each vertex of every single mesh has been moved considering a reasonable arbitrary displacement range of $+/-3 \mathrm{~mm}$. In the second imperfect model, named "imperfections 2", both fabrication and assembly errors are considered. The fabrication imperfections are generated using the same range as before $(+/-3 \mathrm{~mm})$, while the assembly imperfections are generated considering a reasonable range of $+/-2 \mathrm{~mm}$. 


\section{NUMERICAL ANALYSIS}

In this section, the results of the analyses conducted on the three digital models are presented. For each case, the internal stress state in the initial configuration and during the applied vertical settlement is described.

\subsection{Perfect digital model}

In the initial configuration (self-weight), the flow of forces computed from the postprocessed results calculated by 3DEC, showed an internal stress state compatible with the slight displacements allowed by the geometry, which in turn depend by the two joint stiffnesses specified. As shown in Fig. 4.a, in the initial configuration, the flow of forces is quite vertical and deviates around the openings as expected.

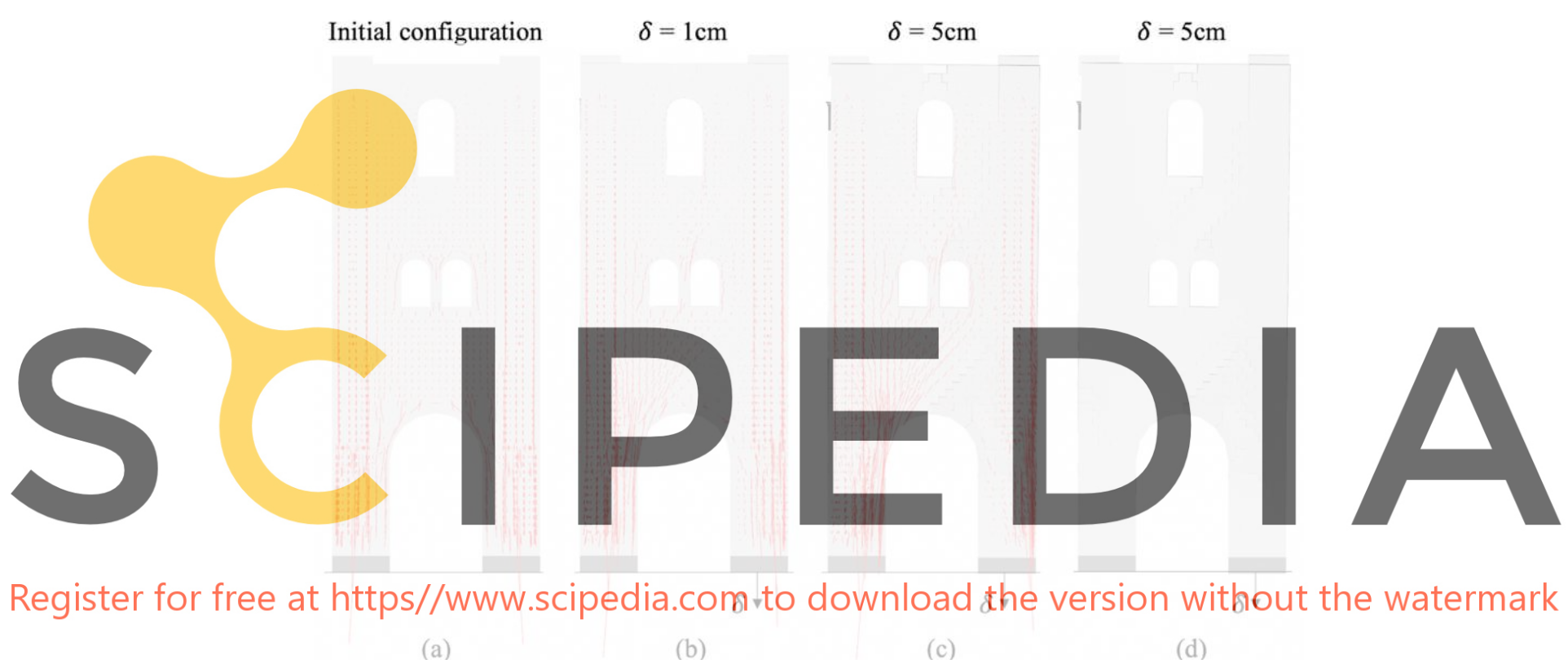

Figure 4. Front view: flow of forces in the initial configuration (a); after $1 \mathrm{~cm}$ of vertical displacement (b); after $5 \mathrm{~cm}$ of vertical displacement (c); crack pattern after $5 \mathrm{~cm}$ of vertical displacement (d).

After the first step of the vertical displacement $(1 \mathrm{~cm})$, the flow of forces starts changing. Figure $4 \mathrm{~d}$ shows the crack pattern corresponding to the foundation displacement of $5 \mathrm{~cm}$; in particular, diagonal fractures can be easily recognised. Cracks represent a discontinuity in the structure, where contact forces cannot go through. For this reason, the flow of forces changes direction as clearly visible in Figures 4.b-c and 5.b-c. Furthermore, the internal stress state of pillar $\mathrm{D}$, subjected to the vertical settlement, changes, and the forces deviate towards the right corner in the front view and to the left corner in the lateral view. This phenomenon is caused by the combination of the vertical settlement and the thrust exerted by the flying buttress at the top of pillar D. 


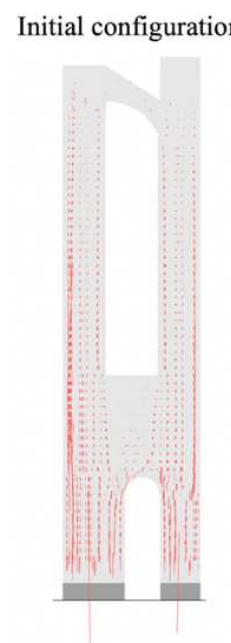

(a)

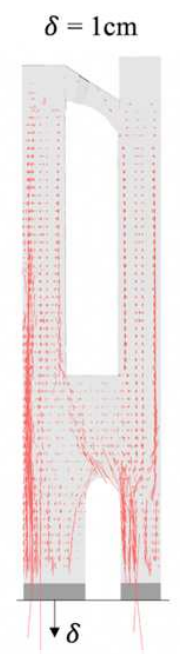

(b)

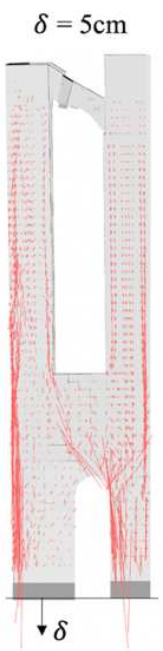

(c)

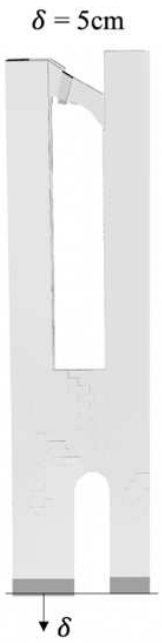

(d)

Figure 5. Lateral view: flow of forces in the initial configuration (a); after $1 \mathrm{~cm}$ of vertical displacement (b); after $5 \mathrm{~cm}$ of vertical displacement (c); crack pattern after $5 \mathrm{~cm}$ of vertical displacement (d).

\subsection{Digital models with geometrical imperfections}

In this section, we present the results of the analyses of the two digital models with

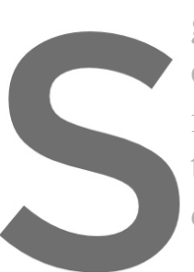
geometrical imperfections applied. In Figur configuration is compared with the flow of forces in the perfect

it is less regular because the geometrical

the blocks, i.e. they

distributed cracks alread

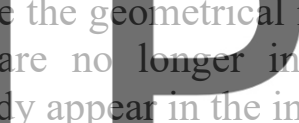

appear

perfect geometry

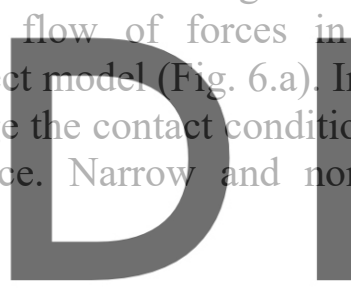

imperfections 2

Register for free at https//www.scipedia.com to download the version without the watermark

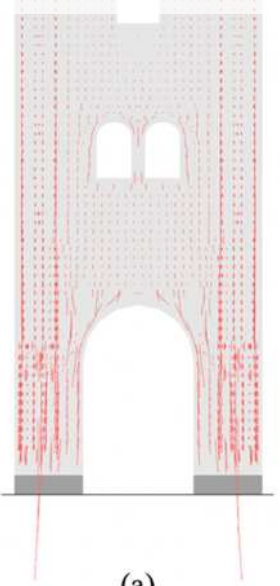

(a)

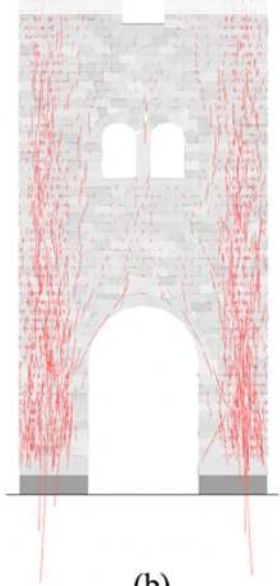

(b)

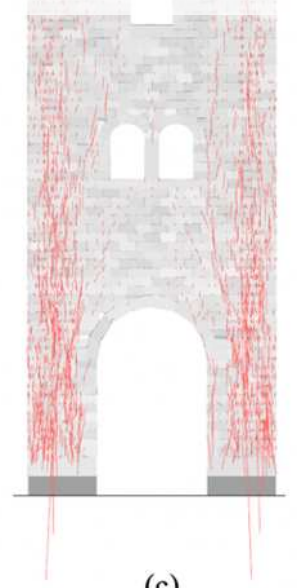

(c)

Figure 6. Flow of forces in the initial configuration: perfect digital geometry (a); imperfections 1 (b), and imperfections 2 (c). 
The resulting internal stress state is slightly different between the two cases with geometrical imperfections. Arbitrary concentrations of forces are visible, and they have an influence on the distribution of the resultant forces on the four supports as will be discussed in the Section 5 .

In Fig. 7, the results of the two models with applied geometrical imperfections subjected to the vertical displacement of pillar D are shown. As soon as the vertical displacement of the pillar occurs, the internal stress state of the structure gets dominated by the effect of the displacement.

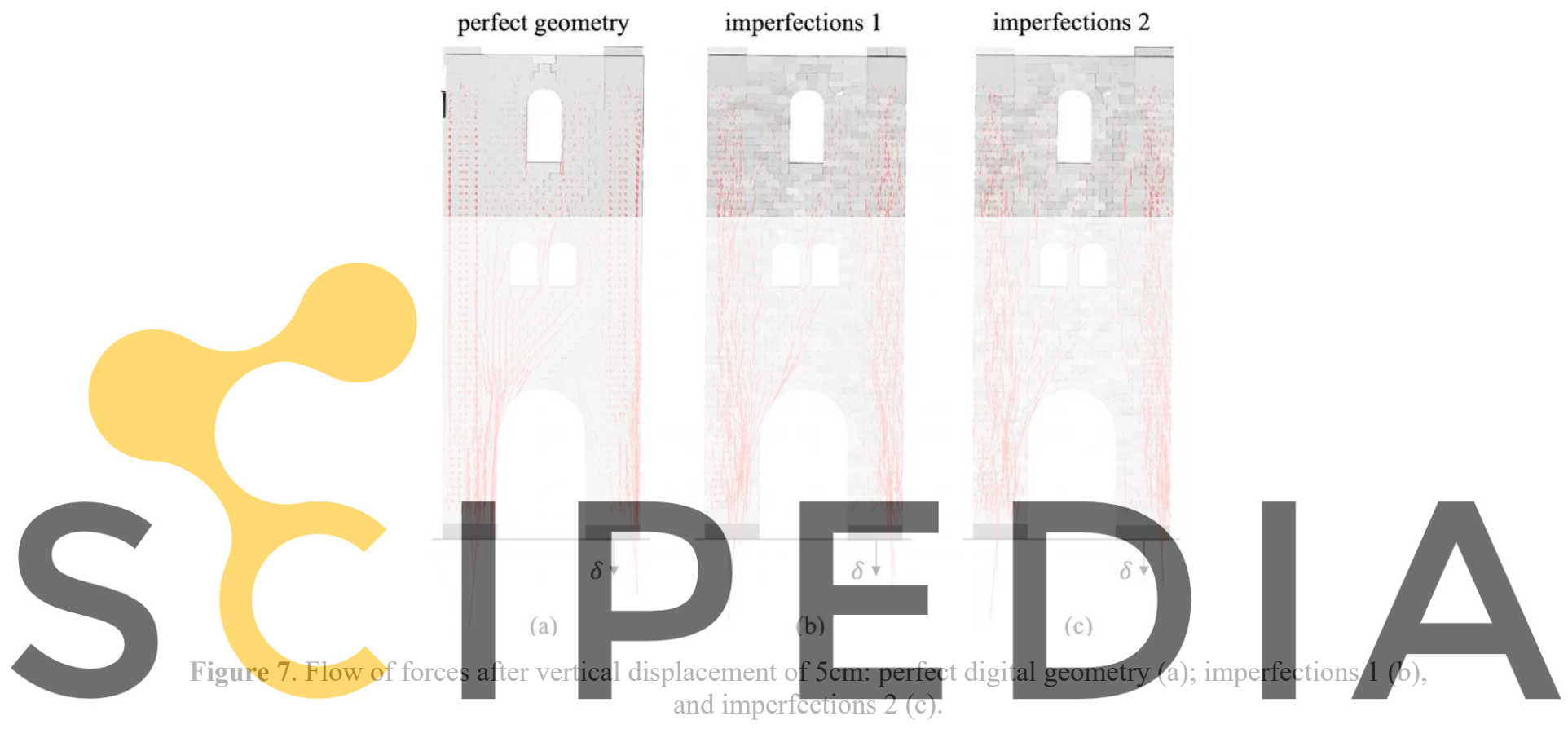

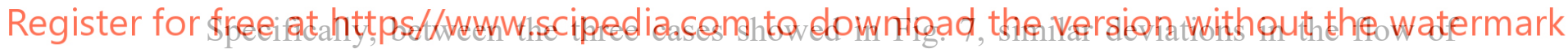
forces can be easily recognised. Qualitatively, the results are similar, even though, we can state that geometrical imperfections affect the position and the number of the cracks.

\section{DISCUSSION}

In this section, the results obtained with the perfect and imperfect digital models are compared in terms of stress state (both in the initial and deformed configuration), crack patterns and thrusts exerted on the supports.

\subsection{Internal stress state in the initial configuration}

In the initial configuration, the perfect model shows a regular distribution of the forces, that flow around the openings in the main wall, compatibly with the boundary conditions. Conversely, the models with geometrical imperfections show a more chaotic distribution but still in accordance with the boundary conditions. This chaotic distribution reflects the nonperfect contacts between the blocks. Since every real structure has a certain amount of imperfections, impossible to reproduce, these results can only give some hints of what could be a more realistic internal stress state. Furthermore, it shows how geometrical imperfections 
indirectly represent an irregular distribution of stress-states even in perfect (undeformed) initial configurations. Irregularities can concentrate forces in some areas or create non-homogeneous loading conditions even in contiguous blocks, as previously shown in [22].

\subsection{Crack patterns}

In the second step, when pillar D is subjected to a vertical displacement, cracks open and the internal stress state changes accordingly. In the model with perfect geometry, the cracks are more visible and localised. Based on the experience and on [23], the crack pattern and its inclination were compatible with the type of settlement applied. In the model with geometrical imperfections, smaller cracks open in more locations, shifted to the left or the right compared to the position of the cracks in the perfect geometry, but, keeping the same average inclination. These results provide an important insight and warning for engineers in practice since they show that, due to imperfections, the same settlement can cause different crack patterns.

\subsection{Internal stress state after the vertical settlement}

For both perfect geometry and the models with geometrical imperfections, the flow of forces deviated to avoid the cracks, going towards pillars C and B. In the initial steps of the displacement, in the model with geometric imperfections, the directions of the resultants on the supports are still influenced by the directions in the initial configuration. With the increasing of the displacement, i.e. increasing reduction of static indeterminacy, the resultants on the supports

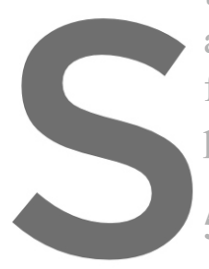
are less dependent on th

forming. The resulting perfect geometry.

5.4 Analysis of the resultants on the supports
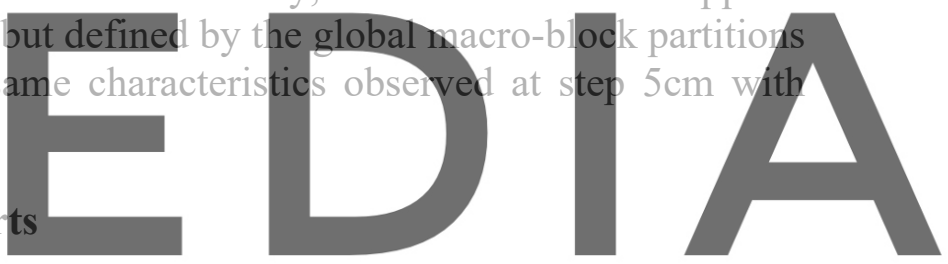

In Fig. 8, the resultants on the supports for the perfect digital geometry, imperfections 1 and

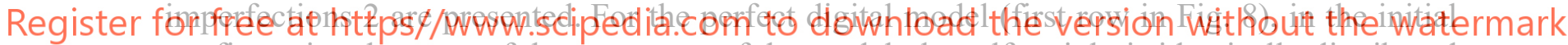
configuration, because of the symmetry of the model, the self-weight is identically distributed between the left and right pillars, as shown by the percentages. At the base of the two frontal pillars, $\mathrm{C}$ and $\mathrm{D}$, the arched openings result in thrusting in the plane of the main wall, with thus resultants directed outwards as well (west and east). Once the vertical displacement starts, after $1 \mathrm{~cm}$, a redistribution of the self-weight among the four pillars can be observed. The percentage of self-weight carried by pillar D decreased while the self-weight carried by pillars $\mathrm{C}$ and $\mathrm{B}$ increased. The resultant of pillar $\mathrm{D}$ and its point of application rotated and moved in direction south-east, respectively. The deviation of the flow of forces towards pillars $\mathrm{C}$ and $\mathrm{B}$, as mentioned in Section 4.1, is easily to be recognised by looking at the directions of their resultant thrusts, west for pillar C and north for pillar B. With the increasing of the displacement $(5 \mathrm{~cm})$, the results showed the same trends. Moreover, the application points of the resultants moved towards the south for pillar C, east for pillar B and south-east for pillar D.

In the cases with geometrical imperfections (second and third rows of Fig. 8), the analysis of the resultant thrusts on the supports confirms the clear influence of imperfections in the initial configuration. Their directions and application points are slightly different and the distribution of the self-weight on each pillar is not anymore symmetrical. This difference leads to a different position of the resultants on the supports during the settlement. After the first step of the 
displacement, the percentage of self-weight carried by the moving pillar D did not drop by the same amount as for the perfect model, but a bit less, showing how imperfections can mitigate the effects due to the variations of the boundary conditions. Consequently, C and B carried less self-weight than before.

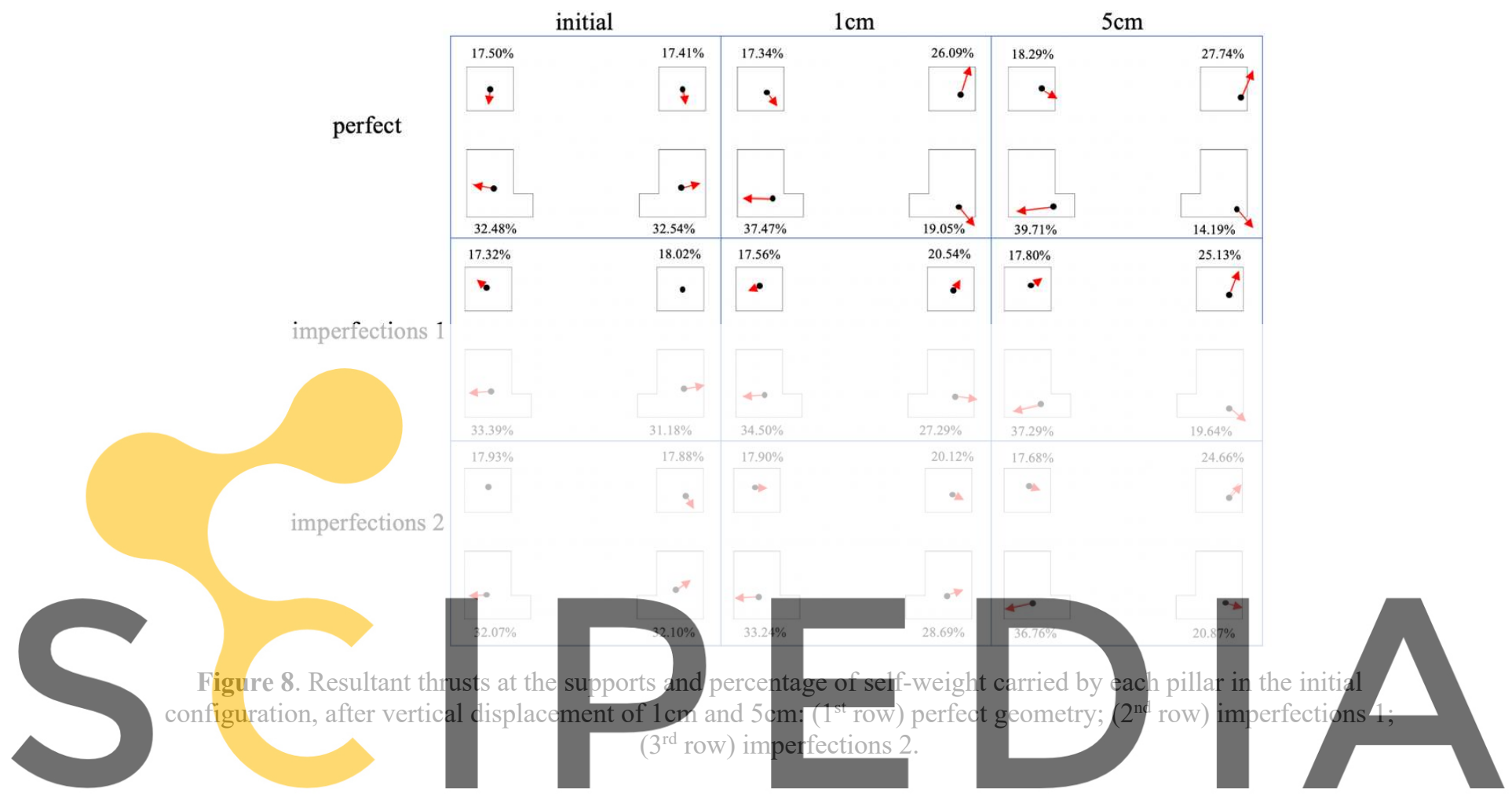

As shown in Fig. 9, in the three cases the self-weight carried by pillar D decreases with the

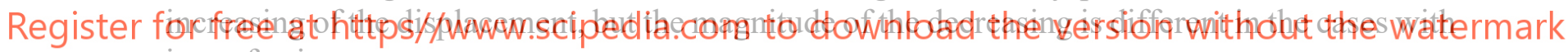
imperfections.

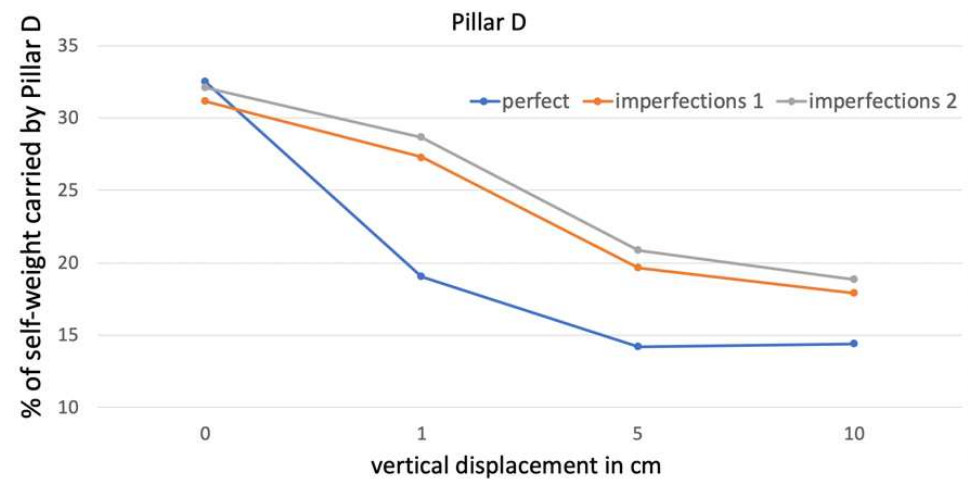

Figure 9. Percentage of self-weight carried by pillar D in the three models, in the initial configuration and after the displacement.

As soon as the displacement increased, at step $5 \mathrm{~cm}$, the directions become very similar to the ones observed in the test with perfect geometry, and the further investigation shown in Fig. 9 
until step $10 \mathrm{~cm}$ shows this tendency even for the percentage of self-weight carried by pillar D. This phenomenon showed that at a certain step of the settlement, the global mechanism and displacement dominates the internal stress state more than geometrical imperfections.

\section{CONCLUSIONS}

This paper investigates the influence of vertical settlements and geometrical imperfections on the internal stress state of a 3D digital model of an URM structure. All the models have been analysed first in their perfect configuration, applying an increasing foundation displacement. In both cases, the crack pattern and the corresponding flow of forces were used to compare the three models. In particular, we noticed that geometrical imperfections mainly influence the initial internal stress state of the structure, and thus, the location and value of the thrusts exerted on the supports. This perfectly fits one of the key points of Limit Analysis as stated in [24], that is, finding the actual stress state in masonry structures is impossible. Geometrical imperfections always belong to real structures and the analyses conducted in this work show that trying to find the actual stress state is worthless. However, though they affect the perfect configuration, as soon as the settlement occurs, the flow of forces is dominated more by the foundation displacement than by geometrical imperfections. Only slight variations locally in the crack pattern are recognisable in the models with imperfections compared to the perfect one. This exploration also suggests another strategy that could be relevant for practical problems in which settlements and specific crack patterns have been observed. In order to calibrate the DEM model, we propose to generate a sufficiently large set of models with imperfections applied, to compare the results with the observed state in reality. The model that matches the best can then be used to do further assessment, as understanding the displacement capacity or the stability after a seismic event. The two typologies of applied imperfections analysed shown a similar effect on the internal stress state, but further investigation is required to understand their respective influence; and, to study the range of stability in the initial configuration due to imperfections, which modify the application points of the resultant thrusts.

Acknowledgements. This work was supported by the Swiss National Science Foundation (SNSF) - project grant \#178953: "Practical Stability Assessment Strategies for Vaulted Unreinforced Masonry Structures”.

\section{REFERENCES}

[1] Heyman, J. The stone skeleton. Int. J. Solids. Struct. (1966) 2:249-279.

[2] Block, P., Ciblac, T. and Ochsendorf, J. Real-time limit analysis of vaulted masonry buildings. Comput. Struct. (2006) 84:1841-52.

[3] Huerta, S. Mechanics of masonry vaults: The equilibrium approach. In: 3rd Int. Semin. Hist. Constr. Guimarães, Port (2001), pp. 47-70.

[4] Block, P. Thrust Network Analysis: Exploring Three-dimensional Equilibrium. PhD Thesis (2009).

[5] Block, P. and Lachauer, L. Three-dimensional funicular analysis of masonry vaults. Mech. Res. Commun. (2014) 56:53-60.

[6] Fraternali, F., Angelillo, M. and Fortunato, A. A lumped stress method for plane elastic problems and the discrete-continuum approximation. Int. J. Solids. Struct. (2002) 
39:6211-6240.

[7] Fraternali, F. A thrust network approach to the equilibrium problem of unreinforced masonry vaults via polyhedral stress functions. Mech. Res. Commun. (2010) 33:198-204.

[8] Angelillo, M. and Fortunato, A. Equilibrium of masonry vaults. In: Novel approaches in civil engineering, Springer, Berlin, Heidelberg (2004), pp.105-111.

[9] Angelillo, M., Babilio, E. and Fortunato, A. Singular stress fields for masonry-like vaults. Contin. Mech. Thermodyn. (2013) 25:423-441.

[10] Angelillo, M., Fortunato, A., Gesualdo, A., Iannuzzo, A. and Zuccaro, G. Rigid block models for masonry structures. Int. J. Mason. Res. Innov. (2018) 3(4):349-368.

[11] Cundall, P.A. A computer model for simulating progressive large-scale movements in blocky rock systems. Proocedings Int. Symp. Rock Mech. Nancy 2 (1971).

[12] Itasca Consulting Group I. 3DEC - Three-Dimensional Distinct Element Code, Ver. 5.2. Minneapolis: Itasca (2016).

[13] Cundall, P.A. Formulation of a three-dimensional distinct element model-Part I. A scheme to detect and represent contacts in a system composed of many polyhedral blocks. Int. J. Rock Mech. Min. Sci. (1988) 25(3):107-116.

[14] Hart, R., Cundall, P.A. and Lemos, J. Formulation of a three-dimensional distinct element model-Part II. Mechanical calculations for motion and interaction of a system composed of many polyhedral blocks. Int. J. Rock. Mech. Min. Sci. (1988) 25(3):117125.

[15] Lemos, J. Discrete Element Modelling of Masonry Structures Int. J. Archit. Herit. (2007) 1(2):190-213.

[16] Van Mele, T., McInerney, J., DeJong, M.J. and Block, P. Physical and Computational Discrete Modelling of Masonry Vault Collapse. SAHC (2012) 2552-2560.

[17] DeJong, M.J. and Vibert, C. Seismic response of stone masonry spires: Computational and experimental modeling. Eng. Struct. (2012) 40:566-574.

[18] McInerney, J.and DeJong, M.J. Discrete Element Modeling of Groin Vault Displacement Capacity. Int. J. Archit. Herit. (2015) 9(8):1037-1049.

[19] Dell'Endice, A., Iannuzzo, A., DeJong, M.J., Van Mele, T. and Block, P. Modelling imperfections in unreinforced masonry structures: Discrete Element simulations and scale model experiments of a pavilion vault. Eng. Struct. (2021) 228: 111499.

[20] Simon, J.and Bagi, K. Discrete Element Analysis of the Minimum Thickness of Oval Masonry Domes. Int. J. Archit. Herit. (2016) 10(4):457-475.

[21] Iannuzzo, A., Dell'Endice, A., Maia Avelino, R., Kao, G.T.C., Van Mele, T. and Block, P. COMPAS Masonry: a computational framework for practical assessment of unreinforced masonry structures. In: Proceedings of the SAHC Symposium, Barcelona: (2021).

[22] Bigoni, D. and Noselli, G.. Localized stress percolation through dry masonry walls. Part I - Experiments. Eur. J. Mech. A/Solids (2010) 29(3):291-298.

[23] Mastrodicasa, S. Dissesti statici delle strutture edilizie. Ulrico Hoepli (1978).

[24] Heyman, J. The structural engineer's view of ancient buildings. J. Mech. Mater. Struct. (2018) 13:609-15. 